\title{
Temperature changes and the ATP concentration of the soil microbial biomass
}

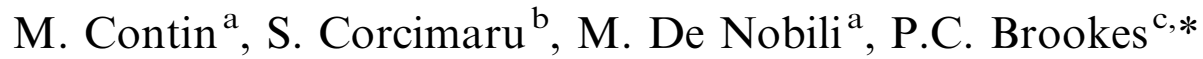 \\ a Dipartimento di Produzione Vegetale e Tecnologie Agrarie, University of Udine, Via delle Scienze, 208-33100 Udine, Italy \\ ${ }^{\mathrm{b}}$ Soil Microbiology Department, Institute of Microbiology, Academy of Sciences of Moldova, Chisinau 2028, Moldova \\ ${ }^{\mathrm{c}}$ Soil Science Department, IACR-Rothamsted, Harpenden, Herts, AL5 2JQ, UK
}

Received 5 May 1999; received in revised form 12 October 1999; accepted 23 February 2000

\begin{abstract}
Two soils from temperate sites (UK; arable and grassland) were incubated aerobically at $0,5,15$ or $25^{\circ} \mathrm{C}$ for up to 23 days. During this period both soils were analysed for soil microbial biomass carbon (biomass C) and adenosine $5^{\prime}$ triphosphate contents (ATP). Biomass C did not change significantly in either soil at any temperature throughout, except during days 0 to 1 in the grassland soil. Soil ATP contents increased slowly throughout the 23 days of incubation, from 2.2 to a maximum of 3.1

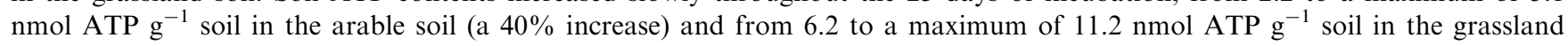
soil (an increase of $81 \%$ ), both at $25^{\circ} \mathrm{C}$. Since biomass $\mathrm{C}$ did not change either with increasing temperature or increasing time of incubation, it was concluded that an increase in ATP was either due to an increase in adenylate energy charge or de novo synthesis of ATP, or both. During the incubation, biomass ATP concentrations ranged from about 5 to $12 \mu \mathrm{mol}$ ATP $\mathrm{g}^{-1}$ biomass $\mathrm{C}$ but trends between biomass ATP and incubation temperatures were not very obvious until about day 13 . On day 23 , biomass ATP concentrations were positively and linearly related to temperature: $\left(\mu \mathrm{mol} \mathrm{ATP} \mathrm{g}^{-1}\right.$ biomass $\mathrm{C}=6.98 \pm 0.35+$ $0.134 \pm 0.023 T^{0}\left(r^{2}=0.77\right)$ with no significant difference in the slope between the grassland and arable soils. At $25^{\circ} \mathrm{C}$ the biomass ATP concentration was $10.3 \mu \mathrm{mol} \mathrm{g}{ }^{-1}$ biomass $\mathrm{C}$, remarkably close to many other published values. It was concluded that, although the biomass increased its ATP concentration in response to increasing temperature, the increase was comparatively small. Also, at all temperatures tested, the biomass maintained its ATP concentration within the range commonly reported for micro-organisms growing expontentially in vitro. This is despite the fact that the biomass normally exhibits other features more typical of a "resting" or dormant population - a paradox which still is not resolved. (C) 2000 Elsevier Science Ltd. All rights reserved.
\end{abstract}

Keywords: Soil microbial biomass; Soil ATP and temperature; Biomass ATP concentration

\section{Introduction}

There is substantial evidence which suggests that the soil microbial biomass maintains an adenosine $5^{\prime}$ triphosphate (ATP) concentration typical of microorganisms undergoing exponential growth in vitro. This high concentration (around 10 to $12 \mu \mathrm{mol}$ ATP $\mathrm{g}^{-1}$ biomass C) is unchanged irrespective of whether

\footnotetext{
* Corresponding author. Tel.: + 44-01582-763133; fax: + 44-01583760981 .

E-mail address: philip.brookes@bbsrc.ac.uk (P.C. Brookes).
}

the soil is unamended, where microbial metabolism is very slow (e.g., Jenkinson and Ladd, 1981), or if readily decomposable substrates, e.g., glucose or plant residues have been recently given, which can trigger intense microbial activity. (e.g., Jenkinson et al., 1979; Jenkinson, 1988; Joergensen et al., 1990; Ocio and Brookes, 1990; Chander and Brookes, 1991).

In some circumstances, this close and consistent relationship does not appear to hold. For example, De Nobili et al. (1996) reported biomass ATP concentrations as high as $35 \mu \mathrm{mol}$ ATP $\mathrm{g}^{-1}$ biomass C 3 days after glucose addition to a UK grassland soil. How- 
ever, this was finally attributed to exocellular ATPase activity in the glucose-amended soil. This caused aberrantly low recoveries of ATP in the "spike", leading to overestimation of biomass ATP once the correction for soil ATP fixation was made.

Cheng-Sheng et al. (1997) also considered that biomass ATP concentrations increased systematically, by up to nearly 3-fold (from about 3.9 to $9.0 \mu \mathrm{mol}$ ATP $\mathrm{g}^{-1}$ biomass $\mathrm{C}$ ), during the first few days following glucose addition to a sandy-loam soil. However, their extraction method was much less vigorous and efficient than ultrasonics as used by others (e.g., Jenkinson and Oades, 1979). Since ATP is such a labile cellular constituent (Karl, 1980) it is essential that the degradative enzymes in the microbial cells are inactivated immediately or ATP will be dephosphorylated and lost. The higher biomass ATP concentrations during the first few days after glucose addition could therefore reflect, at least partially, more efficient extraction of ATP from younger than older cells due to the rather inefficient extraction procedure used.

Jenkinson and Ladd (1981) laid down stringent criteria which must be met if a method is to satisfactorily extract ATP from soil. These are that it must (1) release all the ATP from the biomass; (2) instantly inactivate all the ATP-hydrolysing enzymes in both the biomass and soil; and (3) hold the released ATP in solution against sorption on the soil colloids. In our experience, most results which differ considerably from the mean biomass ATP concentrations cited by Jenkinson (1988) for moist aerobic mineral soils, whether substrate-amended or unamended, usually result from a failure to meet one or more of the above criteria.

Some published data argues against a reasonably consistent concentration of ATP in the microbial biomass (e.g., Ross et al., 1981, 1990; Sparling et al., 1981; Sparling and Eiland, 1983). However, Jenkinson (1988) collated all relevant results in the world literature and found that ATP and biomass C concentrations were very highly correlated over about 45 soils, giving a mean biomass ATP concentration of $11.7 \pm 0.29 \mu \mathrm{mol}$ ATP $\mathrm{g}^{-1}$ biomass C. This was in moist aerobic mineral soils, which received a 'conditioning incubation' of $5-10$ days at $25^{\circ} \mathrm{C}$ before analysis, prior to extraction with strongly acidic reagents under the criteria suggested by Jenkinson and Ladd (1981).

Under these conditions, our picture of the soil microbial biomass is as a large, mainly dormant community with, paradoxically, a high ATP concentration (Jenkinson and Oades, 1979) and adenylate energy charge (Brookes et al., 1983) equivalent to those in micro-organisms growing exponentially in pure culture in vitro. However, this conclusion is based almost exclusively on measurements made on soils given a 'conditioning incubation' under the above, standard, conditions, at $25^{\circ} \mathrm{C}$. In contrast, the biomass in the natural environment normally survives under conditions of moisture and temperature which may fluctuate considerably and rapidly. For example, the subsurface temperature of UK soils may easily range from below $0^{\circ}$ to more than $20^{\circ} \mathrm{C}$ (Payne and Gregory, 1988).

Our aims were to determine whether changes in temperature affected the amounts of ATP and biomass in soil and the ATP concentration of this biomass. This is particularly important because soils are typically given a "conditioning incubation" at $25^{\circ} \mathrm{C}$ for $7-10$ days before biomass measurements. If this incubation significantly changes the concentration of biomass or ATP in soils from that in the population in the field, this would seriously affect the interpretation of measurements of the soil microbial biomass.

\section{Materials and methods}

\subsection{Soils}

Soils were sampled from two field plots of the Highfield Long Term Ley-Arable Experiment at Rothamsted (UK). Soil 1 has been under permanent arable and Soil 2 under permanent grassland, both since 1896 (Johnston, 1973). Both soils were sampled with $5 \mathrm{~cm}$ dia Dutch augers. Soil characteristics are given in Table 1.

Average daily soil temperature at sampling time (17 September 1996) was $15.5^{\circ} \mathrm{C}$ in the top $10 \mathrm{~cm}$ layer. The soils were then hand-picked at this temperature $\left( \pm 1^{\circ} \mathrm{C}\right)$ to remove any obvious plant or animal residues, then sieved at field moisture content $(<2 \mathrm{~mm})$. A portion of both soils was sampled and analysed for their chemical properties just after sieving, while the remaining soils were adjusted to $40 \%$ Water Holding Capacity (WHC) prior to incubation.

\subsection{Incubation conditions}

Immediately after adjustment of soil moisture (Section 2.1) the moist soil samples were incubated at six different temperatures $\left(0,5,10,15,20\right.$ or $\left.25^{\circ} \mathrm{C}\right)$ in the dark, under aerobic conditions at $40 \%$ WHC. For each temperature three separate plastic bags, each containing about $1.5 \mathrm{~kg}$ moist soil were prepared. A single replicate was then removed from each bag for biomass and ATP analysis as required. Biomass $\mathrm{C}$ and soil ATP contents were determined at 1, 3, 6, 13 and 23 days of incubation except that soils incubated at 10 and $20^{\circ} \mathrm{C}$ were analysed only once - after 23 days of incubation. 


\subsection{Analytical measurements}

Biomass carbon $(\mathrm{Bc})$ was measured by the Fumigation-Extraction method (Vance et al., 1987). Moist soil portions, equivalent to $25 \mathrm{~g}$ oven dry soil, were fumigated with ethanol-free chloroform for $24 \mathrm{~h}$. The soils were then extracted with $100 \mathrm{ml} 0.5 \mathrm{M} \mathrm{K}_{2} \mathrm{SO}_{4}$ for $30 \mathrm{~min}$. A set of non-fumigated soils extracted similarly at the time fumigation commenced. Organic $\mathrm{C}$ in the soil extracts was measured by an automated UVpersulphate oxidation procedure (Wu et al., 1990).

Soil ATP was extracted from soil by the TCA reagent, a mixture of $0.5 \mathrm{M}$ trichloro-acetic acid, $0.25 \mathrm{M}$ phosphate and $0.1 \mathrm{M}$ paraquat (Jenkinson and Oades, 1979). In order to estimate the amount of ATP lost in the soil during extraction, for example by adsorption onto soil colloids and by hydrolysis, two different soil extractants were used. Extractant A contained the reagent only, while Extractant B was prepared as Extractant A except that $10 \mathrm{ml}$ of $1 \mathrm{mM} \mathrm{ATP} 1^{-1}$ was added per litre of Extractant $\mathrm{A}$ as the hydrated tetrasodium salt (SIGMA) as internal standard. This gave a final ATP concentration (as the free acid) in Extractant B of 50 pmol $50 \mu 1^{-1}$.

The ATP concentrations in the soil extracts were determined by the fire-fly luciferin-luciferase assay system (Tate and Jenkinson, 1982a). Luciferin was supplied by SIGMA while purified luciferase was supplied by Boehringer-Mannheim. The luciferase was dissolved

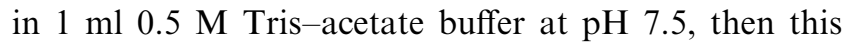
concentrated solution was stored frozen at $-18^{\circ} \mathrm{C}$ in $50 \mu \mathrm{l}$ aliquots in glass vials. (The enzyme remains stable for several months under these conditions). Just before use an aliquot of concentrated enzyme solution was thawed and diluted with $60 \mathrm{mM}$ Tris-albumen buffer $(10 \mathrm{ml}, \mathrm{pH}$ 7.95). The luciferin was dissolved in water to give $500 \mu \mathrm{g} \mathrm{ml}^{-1}$, then added to the enzyme solution and stored over ice.

Counting commenced about $10 \mathrm{~min}$ after enzyme addition. However, with arsenate buffer, the exact time of the start of counting after enzyme addition is relatively unimportant. Indeed, we have obtained perfectly valid, but smaller, counts more than $12 \mathrm{~h}$ after enzyme addition. Bioluminescence was measured using a Packard liquid scintillation counter set out of coincidence. Counts over a $6 \mathrm{~s}$ integration time were compared with a standard curve of ATP prepared in Extractant A.
All results are expressed on an oven-dry soil basis $\left(105^{\circ} \mathrm{C}, 24 \mathrm{~h}\right)$ and are means of three replicate measurements.

\subsection{Statistical analyses}

Standard errors were calculated using approximate error propagation formulae and are given as standard errors of the differences of the means. Regression analysis and analyses of parallelism were carried out using Genstat.

\section{Results and discussion}

\subsection{Changes in biomass $C$ during incubation at different temperatures}

Biomass $\mathrm{C}$ in the arable Soil 1 remained constant at around $275 \mu \mathrm{g}$ biomass $\mathrm{C} \mathrm{g}^{-1}$ soil within the temperature range of 0 to $25^{\circ} \mathrm{C}$ until the end of the incubation on day 23 (Fig. 1). In contrast, biomass $\mathrm{C}$ apparently increased rapidly in the grassland soil, from about 910 $\mu \mathrm{g}$ biomass $\mathrm{C}^{-1}$ soil just after sampling to $1175 \mu \mathrm{g} \mathrm{C}$ $\mathrm{g}^{-1}$ soil by the end of day 1 . After this, it remained constant up to day 23, when the experiment ended.

We have great doubt as to the validity of this apparent large and rapid increase in biomass in such a short time and under conditions where no extraneous substrates were applied. While we have observed similar, unaccountable, initial increases under comparable conditions (e.g., Joergensen et al., 1990), there could simply not be a large amount of readily-assimilatable substrate present to support such huge biomass increases. Chander and Brookes (1991) reported biomass synthesis efficiencies of about $11 \%$ following addition of $1000 \mu \mathrm{g}$ maize- $\mathrm{C} \mathrm{g}^{-1}$ soil 5 days after addition. Thus this large substrate input only produced an additional biomass of about $110 \mu \mathrm{g} \mathrm{C} \mathrm{g}^{-1}$ soil, far less than that reported here. The most likely explanation is an artefact in the methodology (probably because the grassland soil was rather dry) just after incubation commences and which fortunately declines in effect very quickly (Sparling and West, 1989). The effect was not detected in the arable soil, probably because of its higher moisture content when sampled.

After the initial apparent increase, the biomass size remained constant, with no significant differences

Table 1

Soil characteristics

\begin{tabular}{lllllll}
\hline Soil no. & Management & Sampling depth $(\mathrm{cm})$ & $\mathrm{pH}\left(\mathrm{H}_{2} \mathrm{O}\right)$ & Clay content $(\%)$ & ${\text { Organic C }\left(\mathrm{mg} \mathrm{g}^{-1}\right)}_{\mathrm{T}^{2}}$ & Total N $\left(\mathrm{mg} \mathrm{g}^{-1}\right)$ \\
\hline 1 & Arable & $0-23$ & 6.1 & 26 & 16.5 & 1.72 \\
2 & Grassland & $0-10$ & 6.0 & 26 & 34.5 & 3.10 \\
\hline
\end{tabular}


between temperatures. The apparent decreases in biomass by day 23 at 15 and $25^{\circ} \mathrm{C}$ were not statistically significant. Thus the biomass in both soils was insensitive to temperature over the comparatively large range from 0 to $25^{\circ} \mathrm{C}$. This also suggests that the decomposability of soil organic matter was little, if at all, increased with increasing temperature or presumably there would have been some net synthesis of biomass. Since biomass measurements are often done after a soil has received a conditioning incubation, usually of several days at $25^{\circ} \mathrm{C}$, it is reassuring to observe that there were no changes in biomass concentration during this period in either soil, irrespective of the incubation temperature. Of course, an alternative explanation is that the decline in biomass at the higher temperatures was balanced by an increase in the synthesis of new biomass due to enhanced decomposability of the soil organic matter. To investigate that possibility would fall outside the scope of our study.

\subsection{Changes in soil ATP concentrations during incubation}

Soil ATP concentrations did not change markedly during the incubations. The ATP content of the arable soil measured just after sampling and sieving was

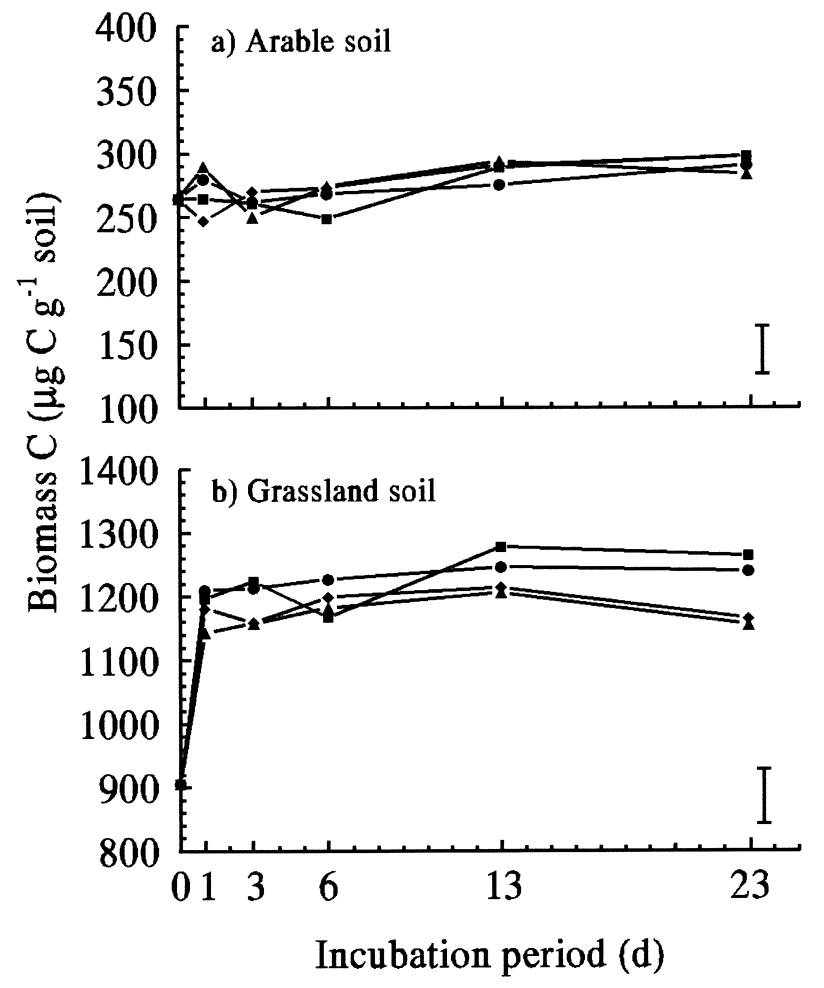

Fig. 1. Changes in biomass $\mathrm{C}$ concentration in soils incubated at 0 $(\boldsymbol{\square}), 5(\bullet), 15(\bullet)$ and $25(\boldsymbol{\Delta}){ }^{\circ} \mathrm{C}$ for up to 23 days. Bars show mean $95 \%$ confidence limits ( 39 and $90 \mu \mathrm{g}$ biomass $\mathrm{C} \mathrm{g}^{-1}$ soil, respectively) for (a) arable and (b) grassland soils $(n=3)$. about $2.2 \mathrm{nmol} \mathrm{ATP} \mathrm{g}^{-1}$ soil. While there were some fluctuations, the only really consistent change was a slightly larger ATP concentration on days 13 and 23 at $25^{\circ} \mathrm{C}$ (Fig. 2a). This gave a final ATP concentration of $3.11 \mathrm{nmol} \mathrm{ATP} \mathrm{g}^{-1}$ soil at $25^{\circ} \mathrm{C}$, an increase of about $40 \%$ compared to the initial ATP concentration.

The grassland soil apparently behaved somewhat differently, although this was probably in part because initial soil ATP concentrations were larger than in the arable soil and so changes were easier to detect (Fig. 2(b)). From an initial value of $6.2 \mathrm{nmol} \mathrm{ATP} \mathrm{g}^{-1}$ soil, it increased to 8.4, 9.4, 10.4 and $11.2 \mathrm{nmol}$ ATP $\mathrm{g}^{-1}$ soil, respectively, at $0,5,15$ and $25^{\circ} \mathrm{C}$ after 23 days of incubation, giving a maximum percentage increase of $81 \%$ at $25^{\circ} \mathrm{C}$. A similar ATP response to temperature occurred in forest humus. Arnebrant and Bååth (1991) reported that incubation at $25^{\circ} \mathrm{C}$ for $1-7$ days gave ca. $50 \%$ larger ATP values than at $4{ }^{\circ} \mathrm{C}$.

While the biomasses in both of our soils showed an increase in ATP with increasing temperature, the increases were relatively small, not even doubling between $0^{\circ} \mathrm{C}$ and $25^{\circ} \mathrm{C}$ in either case. This, together with the biomass data, indicates that, at any given temperature, ATP is largely a measure of soil biomass content. However, ATP tends much more towards an

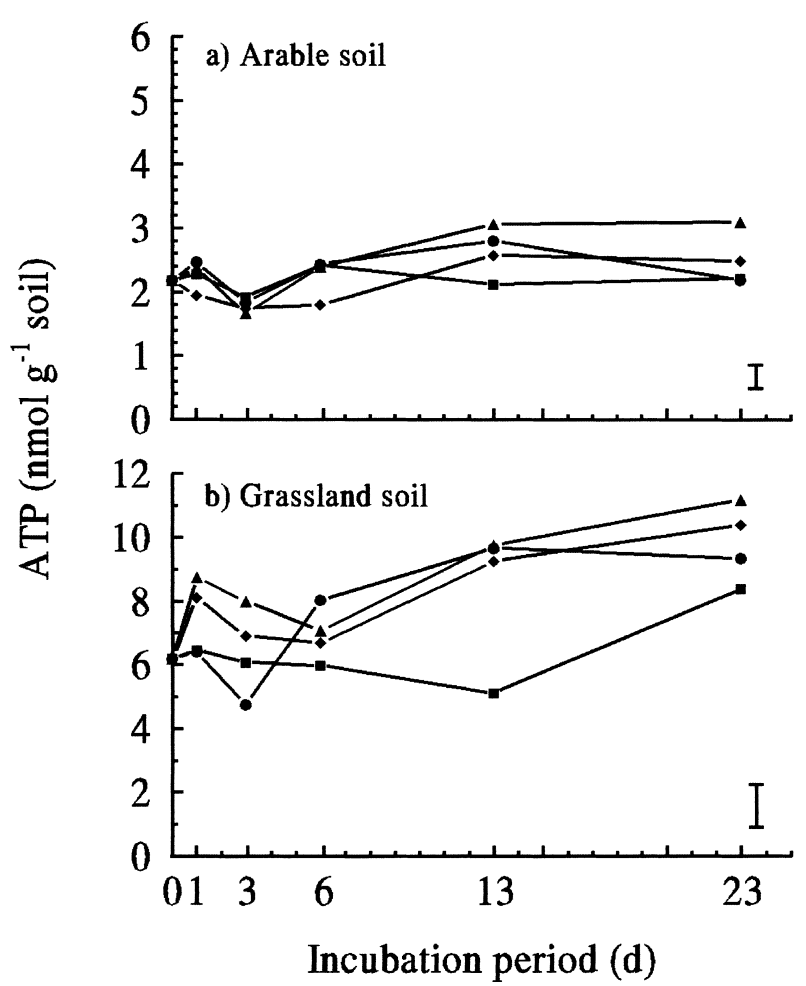

Fig. 2. Changes in ATP concentrations in soils incubated at $0,5,15$ and $25^{\circ} \mathrm{C}$ for up to 23 days. Bars show mean $95 \%$ confidence limits (0.4 and $1.4 \mathrm{nmol} \mathrm{ATP} \mathrm{g}^{-1}$ soil, respectively) for (a) arable and (b) grassland soils $(n=3)$. (Symbols: same as Fig. 1.) 
activity measurement with changing soil temperature, unlike soil biomass $\mathrm{C}$.

It is noteworthy that there were generally increases in ATP following incubation at higher temperatures while biomass $\mathrm{C}$ did not change significantly. Tate and Jenkinson (1982b) similarly reported that ATP increased by $73 \%$ but biomass C by only $23 \%$ when a UK grassland soil was incubated for 7 days at $25^{\circ} \mathrm{C}$. The comparable increases at $10^{\circ} \mathrm{C}$ were $16 \%$ for biomass C and $19 \%$ for ATP. These relatively small increases in total (rather than percentage) ATP do not therefore reflect much change in biomass $\mathrm{C}$ (Fig. 1) but rather increases in ATP synthesis or adenylate energy charge (AEC), or both.

The increases in soil ATP concentration with increasing temperature in both our soils means that if ATP is to be used as an index of biomass then, for maximum accuracy, the ATP must be measured at a standard temperature. It is much less critical that biomass $\mathrm{C}$ measurements are done by $\mathrm{FE}$ at a standard temperature, apparently even within the comparatively wide range of $0-25^{\circ} \mathrm{C}$. There is no experimental reason why $25^{\circ} \mathrm{C}$ should not be the chosen incubation temperature for measurement of biomass $\mathrm{C}$ (Jenkinson and Powlson, 1976) and ATP as proposed by Jenkinson and Oades (1979).

In complete contrast to our findings is the work of Eiland (1985). He reported 4- to 5-fold shifts in soil ATP concentrations at three soil depths between 0 and $20 \mathrm{~cm}$ in a fallow garden soil in Denmark over $24 \mathrm{~h}$. Soil temperature in the $0-3 \mathrm{~cm}$ depth ranged from about 2 to $12^{\circ} \mathrm{C}$ and from 3 to $7^{\circ} \mathrm{C}$ at the $10-20 \mathrm{~cm}$ depth. Overall, the changes in soil ATP concentrations closely followed the fluctuations in soil temperature. We cannot reconcile the differences between our results and those of Eiland (1985). Certainly, the daily temperature fluctuations reported by Eiland (1985) were very much greater than others reported for Northern European soils (e.g., Hay, 1977).

\subsection{Changes in biomass ATP concentrations with temperature}

Knowles (1977) listed the ATP concentrations and AECs of more than 50 micro-organisms growing in culture. Selecting data only from those with an AEC above about 0.75 (i.e., organisms which would be considered to be at a high rate of metabolic activity), 21 cultures of prokaryotic micro-organisms had a mean ATP concentration of $8.0 \pm 0.42$ (standard error) $\mu \mathrm{mol}$ ATP $\mathrm{g}^{-1} \mathrm{C}$, assuming dry cells contain $45 \%$ C. Similar biomass ATP concentrations were reported for eukaryotic microbes in vitro by Knowles. Karl (1980) reported that both exponentially growing prokaryotes and eukaryotic micro-organisms had mean ATP concentrations within the range of about 4.5 to $13 \mu \mathrm{mol}$
ATP $\mathrm{g}^{-1}$ biomass $\mathrm{C}$ (median value around $8 \mu \mathrm{mol}$ ATP $\mathrm{g}^{-1}$ biomass $\mathrm{C}$ ). These microbial biomass ATP concentrations of micro-organisms grown in vitro therefore compare closely with those measured initially in the microbial biomasses of the arable $(8.2 \mu \mathrm{mol})$ and grassland soils $\left(6.8 \mu \mathrm{mol}\right.$ ATP $\mathrm{g}^{-1}$ biomass C). The measurements were made within $1.5 \mathrm{~h}$ of soil sampling. The field soil temperature was $15.5^{\circ} \mathrm{C}$ at the time of sampling and the soils were kept at this temperature $\pm 1^{\circ} \mathrm{C}$ at all soil preparation stages prior to setting up the main incubation experiment (Section 2.2).

During the incubation the soil microbial biomass ATP concentrations ranged from about 5 to $12 \mu \mathrm{mol}$ ATP $\mathrm{g}^{-1}$ biomass $\mathrm{C}$, but trends between biomass ATP concentrations and incubation times did not become readily apparent up to about day 13 (results not given). However, by the end of day 23 of incubation, biomass ATP concentrations were positively and linearly related to temperature: Biomass ATP concentration $\left(\mu \mathrm{mol} \mathrm{ATP} \mathrm{g}^{-1}\right.$ biomass C) $=6.98 \pm 0.35+$ $0.134 \pm 0.023 T^{0}\left(r^{2}=0.77\right)$. There was no significant difference in the slope between the regressions of the arable and grassland soil. The difference in the intercept between the regression of the arable and grassland soil was statistically significant but was not large enough to be meaningful scientifically. It was small (0.85) compared to the errors of the values we are measuring. For simplicity, we used a single line to represent the relationship between temperature and microbial biomass ATP concentration (Fig. 3). At $25^{\circ} \mathrm{C}$ the biomass ATP concentration, meaned between the arable and grassland soils, was $10.3 \mu \mathrm{mol}$ ATP $\mathrm{g}^{-1}$ soil. This is very similar to the mean value of 11.7 $\mu \mathrm{mol}$ ATP $\mathrm{g}^{-1}$ biomass $\mathrm{C}$ reported for the soil microbial biomass by Jenkinson (1988) who collated all

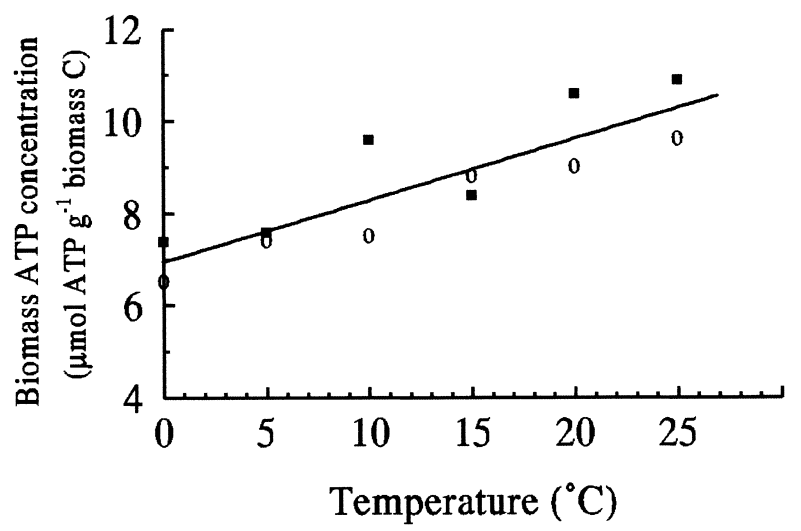

Fig. 3. Biomass ATP concentrations in the arable $(\mathbf{\square})$ and grassland (O) soils incubated at $0,5,10,15,20$ and $25^{\circ} \mathrm{C}$ after 23 days of incubation. Biomass ATP concentration $\left(\mu \mathrm{mol} \mathrm{ATP} \mathrm{g}^{-1}\right.$ biomass $\left.\mathrm{C}\right)=$ $(6.98 \pm 0.35)+(0.134 \pm 0.023) T^{0}$. 
appropriate data then published in the world literature to obtain this value.

It seems quite remarkable that the soil microbial biomass ATP concentrations should be so comparable, especially when comparing analyses taken from the world-wide literature (Jenkinson, 1988) with our two UK soils. It seems even more remarkable that the ATP concentrations of both prokaryotic and eukaryotic micro-organisms growing exponentially in vitro should also compare with the, mainly, dormant (Jenkinson and Ladd, 1981) soil microbial biomass. Indeed, even the mean value of about $7 \mu$ mol ATP $\mathrm{g}^{-1}$ biomass $\mathrm{C}$ at $0^{\circ} \mathrm{C}$ (Fig. 3) fits comfortably within the range of ATP concentrations reported by Knowles (1977) and Karl (1980) for micro-organisms growing exponentially in vitro.

The soil microbial biomass certainly has the capacity to alter its ATP concentration under other circumstances. For example, Brookes et al. (1983) reported that ATP declined from about $77-28 \%$ of total adenine nucleotide content $\left(A_{\mathrm{T}}\right)$ when field moist soil was air-dried, but increased to $67 \%$ of $A_{\mathrm{T}}$ within $2.5 \mathrm{~h}$ of rewetting to the original soil moisture content. Similarly, the ATP contents of a set of previously aerobic soils declined to between $32 \%$ and $64 \%$ of the original ATP contents during 20 days of anaerobic incubation under water. However, on aeration for $1 \mathrm{~h}$, ATP increased to between about $70 \%$ and $84 \%$ of the values in the original aerobic soils (Inubushi et al., 1989).

Why the biomass does not adopt a similar strategy in aerobic soils at low temperatures is unknown. It seems certain that the turnover rates of ATP will increase with increasing temperature (Karl, 1980) even if changes in total amounts of ATP are comparatively small, certainly much smaller than the increases predicted from the $\mathrm{Q}_{10}$ rule.

Joergensen et al. (1990) also reported that ATP concentrations were similar to each other in a grassland soil incubated at 15 or $25^{\circ} \mathrm{C}$ for up to 240 days, with mean declines of $0.11 \%$ and $0.22 \%$ per day. In contrast, the ATP concentrations in other samples of the same soil incubated at $35^{\circ} \mathrm{C}$ declined precipitously, at $1.72 \%$ per day for the first 50 days. Taking all results (except those at $35^{\circ} \mathrm{C}$ ) over the 240 days incubation, the mean biomass ATP concentration was $11.9 \mu \mathrm{mol}$ ATP $\mathrm{g}^{-1}$ biomass $\mathrm{C}$, close to that previously observed under laboratory conditions when moist soils $(40 \%$ WHC) were analysed immediately following a conditioning incubation of several days at $25^{\circ} \mathrm{C}$ (e.g., Oades and Jenkinson, 1979; Jenkinson, 1988).

Despite a wide-ranging literature review, we found no comparable studies to ours, even in chemostat experiments, other than those which we report here. The general picture that emerges from our work and that of most others is that the total biomass concentration in soil is little, if at all, altered by temperatures between $0{ }^{\circ} \mathrm{C}$ and $25^{\circ} \mathrm{C}$. Soil ATP concentration, however, does gradually increase with increasing temperature. The increase is not due to increased synthesis of biomass $\mathrm{C}$ but rather due to either an increase in AEC or de novo synthesis of ATP (or both). Thus, in our work the biomass ATP concentration increased from about 7 to $10 \mu \mathrm{mol}$ ATP $\mathrm{g}^{-1}$ biomass $\mathrm{C}$ within the above temperature range, when measured on day 23 of incubation. It did not therefore deviate from the range of microbial ATP concentrations considered typical of micro-organisms which are growing exponentially (e.g., Karl, 1980; Knowles, 1977) at either end of our temperature range. However, although ATP concentrations are held almost constant it is possible that some microbial groups become active and others become inactive as the temperature changes.

\section{Acknowledgements}

We thank L. Leita, D.S. Jenkinson and D.S. Powlson for useful discussions and C. Grace for help with the experiments.

\section{References}

Arnebrant, K., Bååth, E., 1991. Measurement of ATP in forest humus. Soil Biology \& Biochemistry 23, 501-506.

Brookes, P.C., Tate, K.R., Jenkinson, D.S., 1983. The adenylate energy charge of the soil microbial biomass. Soil Biology \& Biochemistry 15, 9-16.

Chander, K.C., Brookes, P.C., 1991. Microbial biomass dynamics during the decomposition of glucose and maize in metal contaminated and non-contaminated soils. Soil Biology \& Biochemistry 23, 917-925.

Cheng-Sheng, Tsai, Killham, K., Cresser, M.S., 1997. Dynamic response of microbial biomass, respiration rate and ATP to glucose additions. Soil Biology \& Biochemistry 29, 1249-1256.

De Nobili, M., Diaz-Ravina, M., Brookes, P.C., Jenkinson, D.S., 1996. Adenosine 5'-triphosphate measurements in soils containing recently added glucose. Soil Biology \& Biochemistry 28, 10991104.

Eiland, F., 1985. Determination of adenosine triphosphate (ATP) and adenylate energy charge (AEC) in soil and use of adenine nucleotides as measures of soil microbial biomass and microbial activity. Report No. S 1777, State Laboratory for Soil and Crop Research, Copenhagen.

Hay, R.K.M., 1977. Effects of tillage and direct drilling on soil temperature in wheat. Journal of Soil Science 28, 403-409.

Inubushi, K., Brookes, P.C., Jenkinson, D.S., 1989. Adenosine 5'-triphosphate and adenylate energy charge in waterlogged soils. Soil Biology \& Biochemistry 21, 733-739.

Jenkinson, D.S., 1988. The determination of microbial biomass carbon and nitrogen in soil. In: Wilson, J.R. (Ed.), Advances in Nitrogen Cycling in Agricultural Ecosystems. Commonwealth Bureau International, Wallingford, pp. 368-386.

Jenkinson, D.S., Davidson, S.A., Powlson, D.S., 1979. Adenosine triphosphate and microbial biomass in soil. Soil Biology \& Biochemistry 11, 521-527. 
Jenkinson, D.S., Ladd, J.N., 1981. Microbial biomass in soil: measurement and turnover. In: Soil Biochemistry, vol. 5. Marcel Dekker, New York, pp. 415-471.

Jenkinson, D.S., Oades, J.M., 1979. A method for measuring adenosine triphosphate in soil. Soil Biology \& Biochemistry 11, 193199.

Jenkinson, D.S., Powlson, D.S., 1976. The effects of biocidal treatments on metabolism in soil. Part V: A method for measuring soil biomass. Soil Biology \& Biochemistry 8, 209-213.

Joergensen, R.G., Brookes, P.C., Jenkinson, D.S, 1990. Survival of the soil microbial biomass at elevated temperatures. Soil Biology \& Biochemistry 22, 1129-1136.

Johnston, A.E., 1973. The effects of ley and arable cropping systems on the amounts of soil organic matter in the Rothamsted and Woburn ley-arable experiments. Rothamsted Experimental Station Report for 1972, Part 2, pp. 131-159.

Karl, D.M., 1980. Cellular nucleotide measurements and applications in microbial ecology. Microbial Reviews 44, 739-796.

Knowles, C.J., 1977. Microbial metabolic regulation by adenine nucleotide pools. Symposium of the Society for General Microbiology 27, 241-283.

Oades, J.M., Jenkinson, D.S., 1979. Adenosine triphosphate content of the soil microbial biomass. Soil Biology \& Biochemistry 11, 201-204.

Ocio, J.A., Brookes, P.C., 1990. An evaluation of methods for measuring the microbial biomass in soils following recent additions of wheat straw and the characterization of the biomass that develops. Soil Biology \& Biochemistry 22, 685-694.

Payne, D., Gregory, P.J., 1988. The temperature of the soil. In: Wild, A. (Ed.), Russel's Soil Conditions and Plant Growth, 11th ed. Longman Scientific and Technical, Harlow, Essex, pp. 282297.
Ross, D.J., Tate, K.R., Cairns, A., Meyrick, K.F., 1981 Fluctuations in microbial biomass indices at different sampling times in soils from tussock grasslands. Soil Biology \& Biochemistry 13, 109-114.

Ross, D.J., Tate, K.R., Cairns, A., Pansier, E.A., 1990. Microbial biomass estimations in soils from tussock grasslands by three biochemical procedures. Soil Biology \& Biochemistry 12, 375-383.

Sparling, G.P., Ord, B.G., Vaughan, D., 1981. Microbial biomass and activity in soil amended with glucose. Soil Biology \& Biochemistry 13, 99-104.

Sparling, G.P., Eiland, F., 1983. A comparison of methods for measuring ATP and microbial biomass in soils. Soil Biology \& Biochemistry 15, 227-229.

Sparling, G.P., West, A.W., 1989. Importance of soil water content when estimating soil microbial $\mathrm{C}, \mathrm{N}$ and $\mathrm{P}$ by the fumigationextraction methods. Soil Biology \& Biochemistry 21, 245-253.

Tate, K.R., Jenkinson, D.S., 1982a. Adenosine triphosphate measurements in soil: an improved method. Soil Biology \& Biochemistry 14, 331-335.

Tate, K.R., Jenkinson, D.S., 1982b. Adenosine triphosphate (ATP) and microbial biomass in soil: effects of storage at different temperatures and at different moisture levels. Communications in Soil Science and Plant Analyses 13, 899-908.

Vance, E.D., Brookes, P.C., Jenkinson, D.S., 1987. An extraction method for measuring soil microbial biomass C. Soil Biology \& Biochemistry 19, 703-707.

Wu, J., Joergensen, R.C., Pommerening, B., Chaussod, R., Brookes, P.C., 1990. Measurement of soil microbial biomass $\mathrm{C}$ in soil by fumigation-extraction: an improved method. Soil Biology \& Biochemistry 22, 1167-1169. 